\title{
Increased Plasma PCSK9 Levels Are Associated with Reduced Endotoxin Clearance and the Development of Acute Organ Failures during Sepsis
}

\author{
John H. Boyd Christopher D. Fjell James A. Russell Demetrios Sirounis \\ Mihai S. Cirstea Keith R. Walley \\ Centre for Heart Lung Innovation, University of British Columbia, Vancouver, B.C., Canada
}

\section{Key Words}

Sepsis · Lipids · PCSK9

\begin{abstract}
Purpose: We have recently shown that PCSK9 reduces the clearance of endotoxin and is therefore a critical regulator of the innate immune response during infection. However, plasma PCSK9 levels during human sepsis and their relationship to outcomes are not known. Our objective was to determine the relationship between plasma PCSK9 levels and the rate of endotoxin clearance, and then correlate PCSK9 levels with the development of acute organ failures in a cohort of patients with sepsis. Methods: Using human hepatocyte cells, we determined the threshold at which PCSK9 is able to reduce Escherichia coli endotoxin uptake by cultured human hepatocytes. In a single-centre observational cohort at St. Paul's Hospital in Vancouver, Canada, we recruited 200 patients who activated our Emergency Department's sepsis protocol and measured plasma PCSK9 and lipid levels at triage and throughout the admission. Outcomes were the development of sepsis-induced cardiovascular or respiratory failure. Results: We reviewed the literature and determined that the normal human range of PCSK9 found in plasma is
\end{abstract}

$170-220 \mathrm{ng} / \mathrm{ml}$, while levels of $250 \mathrm{ng} / \mathrm{ml}$ and above reduced $E$. coli endotoxin clearance in cultured human hepatocytes. In septic patients, the median levels associated with new-onset respiratory and cardiovascular failure were 370 (250-500) and $380(270-530) \mathrm{ng} / \mathrm{ml}$, respectively, versus 270 $(220-380) \mathrm{ng} / \mathrm{ml}$ in patients who did not go on to develop any organ failure ( $p=0.003$ and 0.005 , respectively). Conclusions: Plasma PCSK9 levels are greatly increased in sepsis. At normal levels, PCSK9 has no influence upon hepatocyte bacterial endotoxin clearance, but as levels rise, there is a progressive inhibition of clearance. During sepsis, PCSK9 levels are highly correlated with the development of subsequent multiple organ failure. Inhibition of PCSK9 activity is an attractive target for treating the spectrum of sepsis and septic shock.

(c) 2016 S. Karger AG, Basel

\section{Introduction}

PCSK9 (proprotein convertase subtilisin/kexin type 9) plays a critical role in regulating circulating cholesterol levels through the reduction of the membrane-associated low-density lipoprotein (LDL) receptor. We have recent-

\section{KARGER}

(C) 2016 S. Karger AG, Basel

1662-811X/16/0082-0211\$39.50/0

E-Mail karger@karger.com

www.karger.com/jin
Dr. John H. Boyd

UBC Centre for Heart Lung Innovation, St. Paul's Hospital

1081 Burrard Street

Vancouver, BC V6Z 1Y6 (Canada)

E-Mail john.boyd@ hli.ubc.ca 
ly shown that PCSK9 increases systemic inflammation and organ failure during infection by reducing the hepatic clearance of bacterial endotoxins via the LDL receptor [1]. Produced and secreted from the liver, production of PCSK9 is normally tightly orchestrated via SREBP transactivation of the PCSK9 promoter region [2]. SREBP transcription factors are cleaved and translocate to the nucleus when there are low levels of cholesterol-derived sterols. In small cohorts of patients it has been reported that some septic patients may have low high-density lipoprotein (HDL), LDL and/or total cholesterol [3-7]. Suppression of cholesterol production has long been appreciated during acute illness, such as acute myocardial infarction; indeed, practice guidelines recommend against measuring lipid profiles following the first day of critical illness because values are lower than at pre-infarct [8].

We hypothesize that during sepsis there is a significant decline in plasma cholesterol with a compensatory increased hepatic PCSK9 production. Alternatively, there have been reports that systemic inflammation directly induces hepatic PCSK9 production [9]. As circulating PCSK9 exceeds a physiologic threshold, it could trap endotoxin in circulation and increase the likelihood of inflammatory organ failure. To test this hypothesis we reviewed the literature and determined the normal plasma levels of PCSK9. We then measured uptake of fluorescently labelled Escherichia coli endotoxin in hepatocytes as a bio-assay to determine the threshold level of PCSK9 at which endotoxin clearance becomes impaired, going on to elucidate the full dose-response curve. To correlate these in vitro findings with patient data we recruited a single-centre cohort of 200 patients who presented at the Emergency Department with sepsis and triggered our institutional sepsis protocol. We obtained plasma at triage and over the subsequent 11 days, measuring plasma PCSK9, LDL, HDL and non-HDL cholesterol and triglycerides. We then compared presenting PCSK9 levels in those who went on to develop sepsis-induced organ failure versus those who did not.

\section{Methods}

\section{Meta-Analysis of Plasma PCSK9 Levels}

We searched MEDLINE between January 1, 1998, and May 2015. The reference lists of retrieved articles and review articles were read manually to augment our search. The search criteria included the terms 'PCSK9' and 'Proprotein convertase subtilisin/ kexin type 9'. One author (J.A.R.) performed the electronic search and listed the studies that were eligible for inclusion in the study. Candidate abstracts were then reviewed and selected for data retrieval. Two authors (J.A.R. and J.H.B.) independently reviewed each study for quality assessment and extracted data on studies and patient characteristics, as well as outcomes, using standardized extraction forms. The studies were assessed for the presence of 2 features: description of the patient sample characteristics and description of the inclusion and exclusion criteria, including statin or fibrate use. Disagreements were resolved through discussion. For each study, the following individual data were extracted: general data (study design), patients (number of included patients, mean age, gender) and PCSK9 plasma levels prior to any intervention (baseline in interventional studies). In our initial search, 26 studies were found and we limited the analysis to those with subjects aged at least 18 years and acute medical process or intervention without a 'baseline' plasma draw. This eliminated 11 studies, leaving 15 for analysis [10-22]. Pooled medians were reported with $95 \%$ confidence intervals.

\section{Hepatocyte Endotoxin Clearance}

The methods have recently been published [1]. Briefly, immortalized human hepatocytes (HepG2 cell line, ATCC) were seeded into a 24 -well plate and grown to $80 \%$ confluence. The culture medium for the duration of the experiment was 80\% DMEM (Invitrogen 11965-065) and 20\% human plasma from pooled healthy donors. For the addition of PCSK9, $3 \mathrm{~h}$ prior to LPS treatment, $4 \mathrm{~h}$ and $19 \mathrm{~h}$ post-treatment cells were treated with $0,250,500$, $1,000,3,000$ and $10,000 \mathrm{ng} / \mathrm{ml}$ of recombinant wild-type human PCSK9 (AcroBiosystems PC9-H5223) or vehicle control. Cells were treated with Alexa Fluor 488-conjugated LPS (Invitrogen L-23351) or with standard non-fluorescent LPS (Sigma L2880) as a control. After $24 \mathrm{~h}$ of LPS treatment, each well was rinsed twice with PBS and detached with Accutase (BD 561527). The cells were collected, washed with PBS, then resuspended in $500 \mu \mathrm{l}$ of PBS and analysed via flow cytometry (Beckman Coulter Gallios ${ }^{\mathrm{TM}}$ Flow Cytometer). Cells were gated via forward and side scatter for viability using previously determined parameters; 20,000 gated cells were counted per sample. The output of interest was the median fluorescence intensity from the instrument's FL1 laser (ex: $488 \mathrm{~nm}$, em: 525/20 nm). Background autofluorescence of cells treated with non-fluorescent LPS was subtracted to determine the fluorescence level resulting from the uptake of the LPS conjugate. Data analysis was performed using Kaluza Analysis 1.3 software (Beckman Coulter).

\section{Early-Sepsis Patient Cohort}

This study was approved by the University of British Columbia, ethics approval H11-00505, and all patients gave written informed consent to the use of both their clinical and analytical data. In a blinded, observational, cohort study, patients with suspected sepsis were identified when the attending Emergency Department physician activated the Institutional Severe Sepsis Order Set (online suppl. table 1; see www.karger.com/doi/10.1159/000442976). Patients were enrolled from January 2011 to July 2013 at St. Paul's Hospital, Vancouver, Canada, at the time of the first microbiological culture drawn for suspected sepsis. Blood was collected in EDTA tubes at the time of initial blood culture and immediately placed on ice. Plasma was separated and two 1-ml aliquots were transferred into barcoded cryovials at $-20^{\circ} \mathrm{C}$ until they were transferred to a secure, alarmed, $-80^{\circ} \mathrm{C}$ freezer. Study identification numbers were assigned to the secured enrolment forms and clinical data was stored in an ORACLE-based database on a firewalled, RSS-encrypted server at St. Paul's Hospital. New cardiovascular dysfunction was defined as treatment with a vasopressor (norepi- 
Fig. 1. Meta-analysis of 15 studies with a total of 3,556 subjects not on statins or fibrates. Studies were weighted according to the number of subjects, and the final pooled 95\% confidence interval for plasma PCSK9 levels was $170-220 \mathrm{ng} / \mathrm{ml}$.

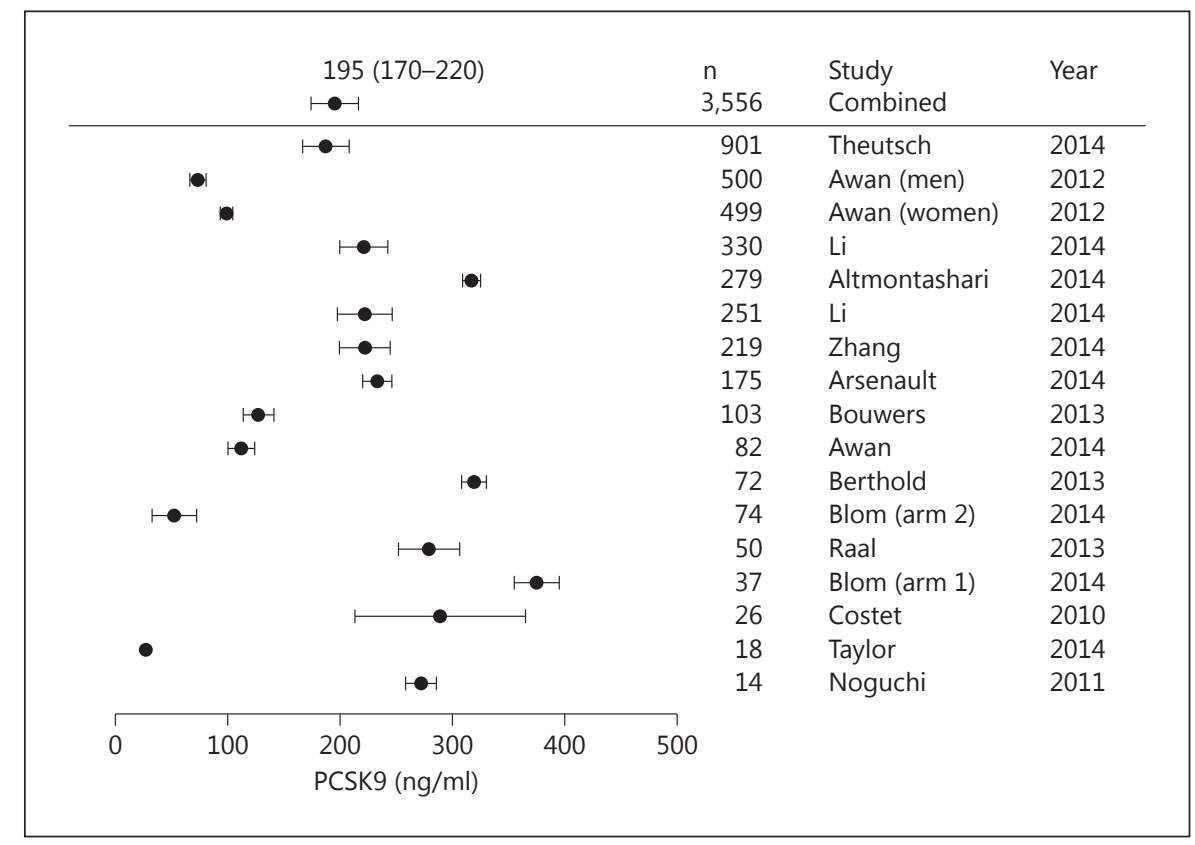

nephrine, epinephrine, phenylephrine), new respiratory dysfunction as the need for mechanical ventilation and $\mathrm{PaO}_{2} / \mathrm{FiO}_{2}<300$ $\mathrm{mm} \mathrm{Hg}$, coagulopathy as platelet count $<80 / \mu \mathrm{l}$, and hepatic dysfunction as bilirubin $>34 \mu \mathrm{mol} / \mathrm{l}$. For acute kidney injury (AKI) we considered organ failure as stage 2 or $3 \mathrm{AKI}$ according to the current KDIGO guidelines based on serum creatinine (SCr; www. kdigo.org) [23] which is a modification of the AKIN classification [24]. An AKI (stage 1) was defined as an SCr rise of $\geq 26.5 \mu \mathrm{mol} / \mathrm{l}$ within $48 \mathrm{~h}$ or an SCr $\geq 1.5$-fold increase from the baseline reference value. Stage $2 \mathrm{AKI}$ was defined as a $\geq 2.0$ - to 2.9 -fold increase from the baseline reference SCr. Stage 3 AKI was defined as a $\geq 3$ fold increase from baseline reference SCr, or an increase of 354 $\mu \mathrm{mol} / \mathrm{l}$ or commencement of renal replacement therapy irrespective of the stage of AKI. The reference SCr is defined as the lowest creatinine value recorded within 3 months of the event, or from repeat SCr within $24 \mathrm{~h}$, or estimated from the nadir SCr value if a patient recovered from AKI, as previously applied [25]. Patients with chronic kidney disease, defined as being on chronic dialysis at admission, were excluded. The urine output criterion for the diagnosis of AKI was not used in this study.

Plasma Lipids and PCSK9 Levels

Plasma PCSK9 was measured via ELISA (R\&D Systems DPC900) using the manufacturer's recommended protocol. As per the manufacturer's product information and direct communication, the upper limit of healthy volunteer plasma PCSK9 using this assay is less than $250 \mathrm{ng} / \mathrm{ml}$. Lipid profiles (total cholesterol, HDL cholesterol and triglycerides, TG) were measured by the clinical laboratory at St. Paul's Hospital using the ADIVA 1800 Chemistry System. LDL cholesterol was calculated using the Friedewald equation, whereby LDL cholesterol = total cholesterol - HDL cholesterol - TG/2.2, with all concentrations in $\mathrm{mmol} / \mathrm{l}$. We used the last observation carried forward method to account for missing measurements.

PCSK9 Is Induced during Sepsis

\section{Statistical Analysis}

Dr. Fjell, a biostatistician, oversaw the statistical analysis. $\chi^{2}$ tests, Student's t test, one-way analyses of variance and MannWhitney U test were used to assess the distributions of PCSK9 and lipids between the groups of patients with or without organ failures. All statistical analyses were performed using R (v.2.8.1; www.R-project.org), SPSS 14.0 software system (SPSS) or GraphPad Prism 5.0 (Graph-Pad, La Jolla, Calif., USA).

\section{Results}

Pooling 3,556 subjects from 15 studies published between 2010 and 2014, we found that the normal range of plasma PCSK9 in patients not on statins or fibrates to be 170-220 ng/ml (fig. 1). The highest reported value in these outpatient cohorts was $2,500 \mathrm{ng} / \mathrm{ml}$. In our previous work we found that at supra-physiological doses of PCSK9 $(3,000 \mathrm{ng} / \mathrm{ml})$ there is nearly complete inhibition of hepatocyte LDLR expression and a consequent $60-65 \%$ reduction in bacterial endotoxin uptake [1]. Here we extend our work to analyse how concentrations between 0 and 3,000 ng/ml (reflecting human plasma PCSK9) altered E. coli endotoxin uptake (fig. 2). In preliminary dose-response experiments, we determined that $250 \mathrm{ng} / \mathrm{ml}$ was the lowest concentration of PCSK9 capable of reducing hepatocyte endotoxin uptake. While statistically significant ( $\mathrm{p}<0.001$ ) due to the 20,000 cells per measurement, the biological effect at $250 \mathrm{ng} / \mathrm{ml}$ was a modest $4 \%$ reduc- 


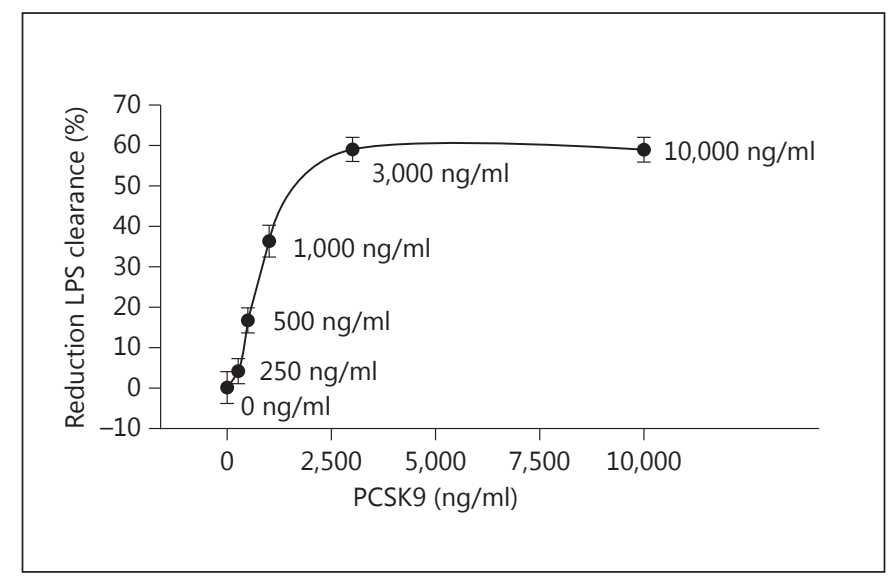

Fig. 2. PCSK9 level is positively correlated with the inhibition of hepatocyte endotoxin uptake. The elimination and detoxification of bacterial endotoxin (LPS) is done almost exclusively via the liver. We used genetically identical human liver cells to evaluate the threshold and dose-response characteristics of the PCSK9 level compared to the rate of LPS uptake into the liver and, thus, clearance from the circulation. A total of 20,000 cells were pooled for each data point and the data are representative of three separate experiments. Compared to no PCSK9 (0 ng/ml), at $250 \mathrm{ng} / \mathrm{ml}$, there is a statistically significant but biologically small (4\%) reduction in LPS uptake. Saturation of the dose-response occurs at 3,000 $\mathrm{ng} / \mathrm{ml}$ with a $60 \%$ reduction in endotoxin uptake. The steepest portion of the PCSK9 dose-response slope occurs between 250 and $1,000 \mathrm{ng} / \mathrm{ml}$. All doses of PCSK9 tested in this curve were significantly different to $0 \mathrm{ng} / \mathrm{ml}(\mathrm{p}<0.05)$.

Table 1. Baseline demographics $(n=200)$

\begin{tabular}{lc}
\hline Age, years & $57 \pm 17$ \\
Male & $130(65)$ \\
Hypertension & $71(36)$ \\
CHF & $20(10)$ \\
COPD & $42(21)$ \\
Chronic renal failure & $24(12)$ \\
Diabetes & $50(25)$ \\
Chronic liver disease & $11(6)$ \\
pH at triage & $7.29(7.25-7.34)$ \\
WBC at triage & $12(10.3-13.6)$ \\
Creatinine at triage, $\mu$ mol/l & $134(107-161)$ \\
Lactate at triage, mmol/l & $2.5(2.0-3.0)$ \\
Hb at triage, g/l & $116(112-120)$ \\
Platelets at triage & $225(203-247)$ \\
Mean arterial pressure at triage, $\mathrm{mm} \mathrm{Hg}$ & $65(61-69)$ \\
Respiratory rate at triage & $25(22-28)$ \\
Heart rate at triage & $102(94-110)$ \\
Statin use & $57(29)$ \\
\hline
\end{tabular}

Data are presented as the mean $\pm \mathrm{SD}, \mathrm{n}(\%)$ or value (range). $\mathrm{CHF}=$ Congestive heart failure; $\mathrm{COPD}=$ chronic obstructive pulmonary disease; $\mathrm{WBC}=$ white blood cell count. tion in endotoxin uptake. We saw a steep reduction in endotoxin uptake as PCSK9 levels exceeded $250 \mathrm{ng} / \mathrm{ml}-$ in the plasma PCSK9 range of $250-1,000 \mathrm{ng} / \mathrm{ml}$ there was a linear reduction in endotoxin clearance as PCSK9 levels rose, with a maximum $60 \%$ reduction in endotoxin uptake achieved at 3,000 ng/ml PCSK9 (fig. 2). Given this mechanistic knowledge, we went on to examine whether increased PCSK9 plasma levels in a cohort of patients with early sepsis were correlated with the development of acute cardiovascular and/or respiratory failure.

We recruited 200 patients. Patient baseline demographics upon presentation to the Emergency Department and their subsequent organ failures during the admission are shown in table 1 . In keeping with our institution's aggressive approach to activating the sepsis protocol for patients at risk of developing organ failure, this cohort of patients with sepsis had a low (5\%) 28-day mortality. In our cohort of patients with sepsis, $30 \%$ progressed to respiratory failure, $18 \%$ to cardiovascular failure, $30 \%$ to AKI stage 2 or stage 3,14\% to liver failure and $27 \%$ to hematologic failure. Like most sepsis cohorts [1,26-28], this group of patients was $65 \%$ male and middle-aged, with a median age of 57 years.

In these patients with early sepsis blood was obtained within $1 \mathrm{~h}$ after Emergency Department admission as part of the blood culture mandated by our Institutional Sepsis Protocol. This time-point represents the earliest possible assessment of patient plasma following triage and is a unique aspect of this cohort. The majority of patients had very low cholesterol at presentation. Only 31 of 200 patients had a normal lipid profile. Figure 3 demonstrates graphically the individual components of the lipid profile along with our laboratory's normal ranges. The most pronounced shift is a reduction in HDL cholesterol. Total cholesterol and LDL cholesterol are also suppressed, although slightly less so than HDL. Triglycerides remained largely unaffected early in sepsis. In a striking negative correlation with cholesterol, PCSK9 is greatly increased in this cohort (fig. 1). This pattern is consistent with the knowledge that low cholesterol could cause the rise in PCSK9; in contrast, a primary rise in PCSK9 production would increase plasma cholesterol. Chronic statin use is also known to increase PCSK9 levels. We found an exaggerated effect of statins; those on statins had PCSK9 levels at presentation of $381(260-585) \mathrm{ng} / \mathrm{ml}$ versus $281(228-376) \mathrm{ng} / \mathrm{ml}$ in patients not on statins $(\mathrm{p}<$ $0.001)$.

We reasoned that if PCSK9 levels causally contributed to the pathophysiology of human sepsis, then there should be a relationship between PCSK9 levels and sepsis 

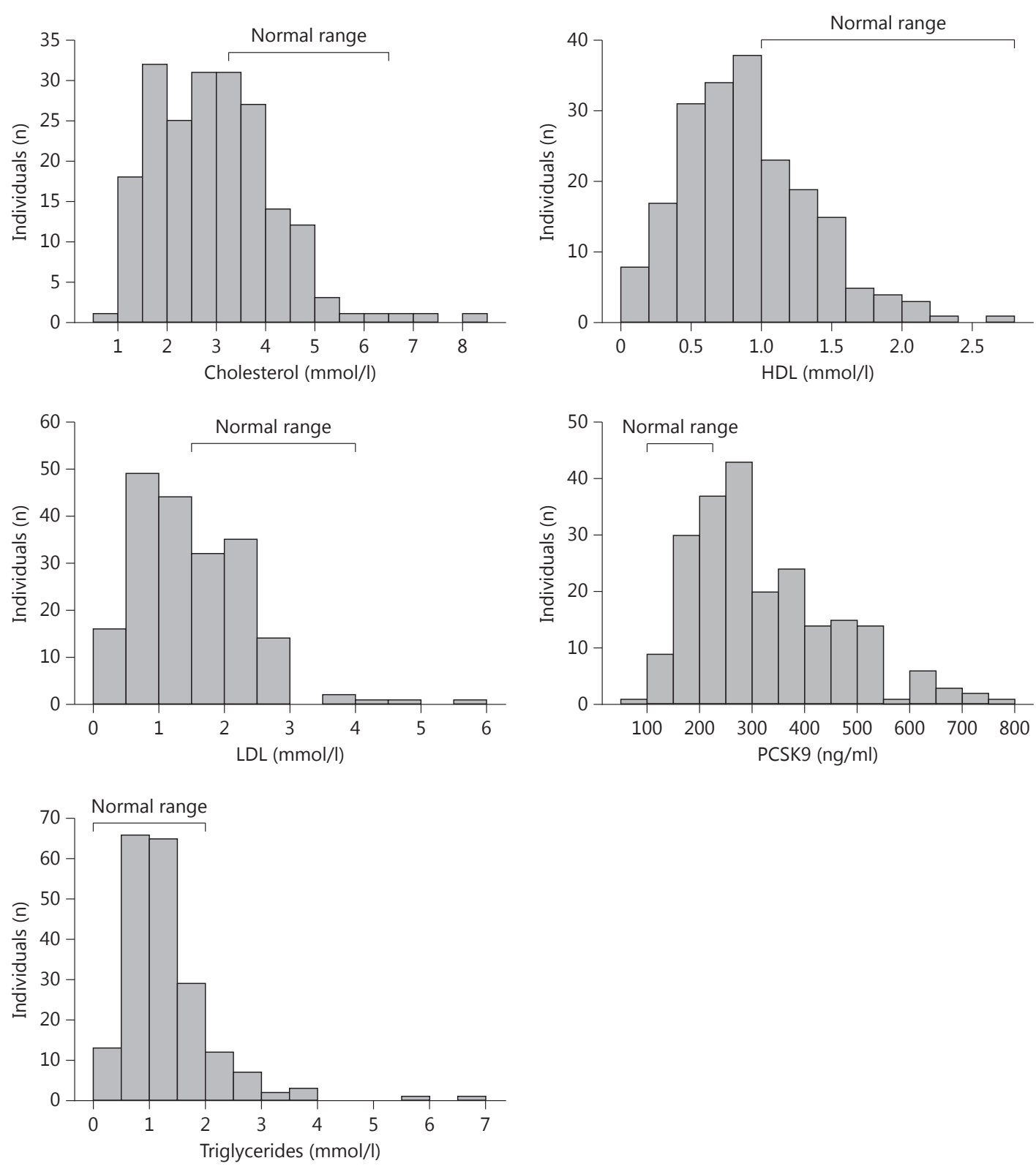

Fig. 3. Lipid and PCSK9 profile at triage in patients assessed for sepsis. Two hundred patients who presented with sepsis and abnormal vital signs triggered the local sepsis protocol and had plasma drawn with the first blood culture. Histogram plots of total cholesterol, HDL, LDL, triglycerides and PCSK9 plasma levels are shown along with normal reference ranges. There is a clear and profound shift towards low cholesterol of all types and high PCSK9. Triglycerides remain largely unaffected early in sepsis. severity. Accordingly, we analysed the odds ratio of developing more than one acute organ failures over the range of plasma PCSK9 levels (fig. 4). Due to the very significant effect of statins on PCSK9, we only analysed patients not on statins $(\mathrm{n}=143)$. As PCSK9 levels exceed the normal range of $170-220 \mathrm{ng} / \mathrm{ml}$, there is a rapid and large increase in the odds of developing multi-organ failure. We went on to analyse PCSK9 levels over the admission according to individual organ failures. In large epidemiological studies of sepsis, cardiovascular and respi- 
Fig. 4. The odds of developing more than one acute sepsis-related organ failure increase as PCSK9 levels exceed the normal range. The upper section displays the fraction of patients not on statins whose triage PCSK9 levels exceed the $\mathrm{x}$-axis threshold. The lower panel plots the odds ratio of developing more than one organ failure in those whose triage PCSK9 levels exceed the $\mathrm{X}$-axis threshold versus those at or below it. Standard error estimates are plotted in grey.

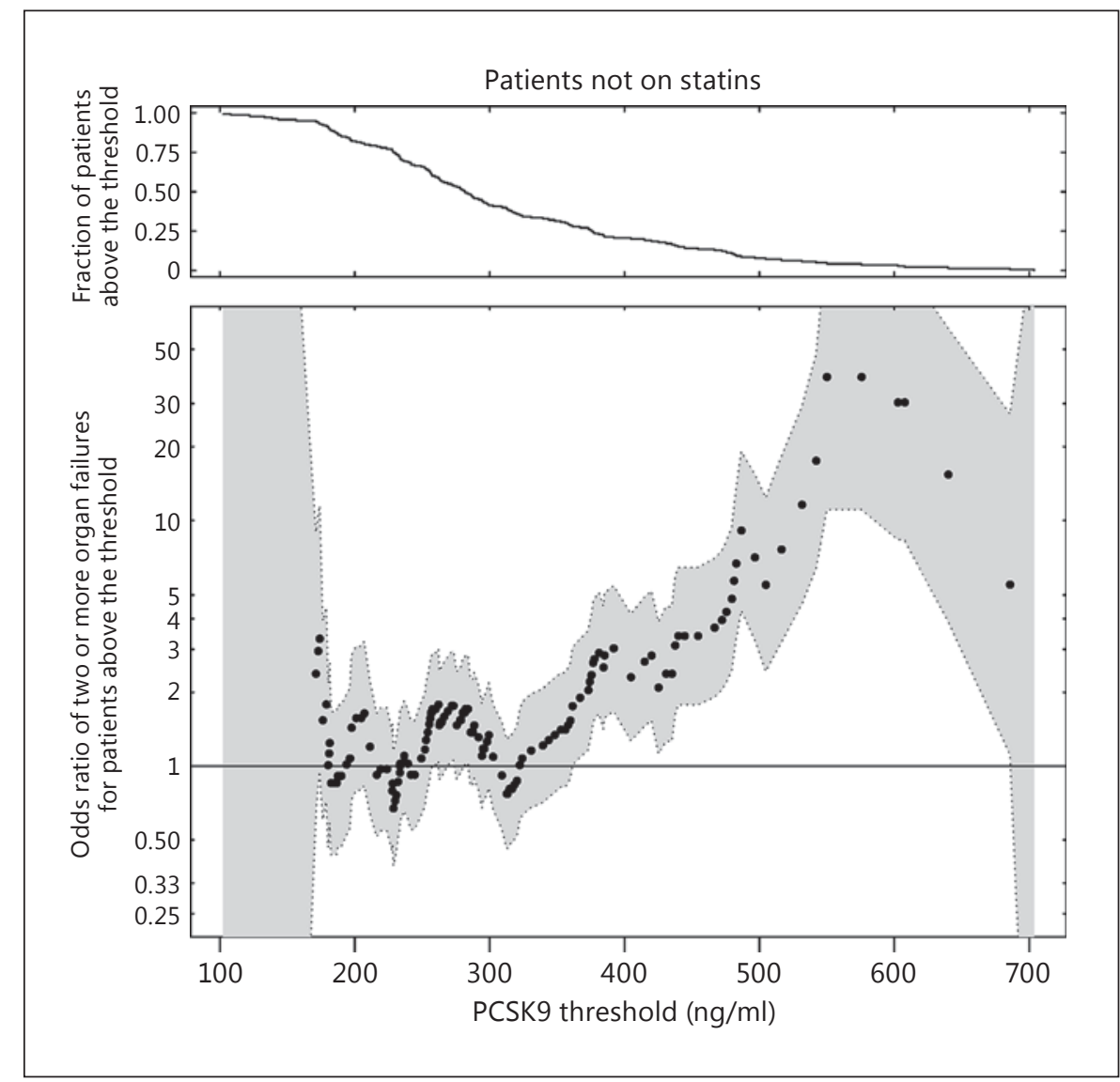

ratory failure is responsible for the vast majority of early organ failure [29]. Therefore, to increase the clinical relevance of our analysis we selected patients who developed cardiorespiratory failure as a result of their sepsis and compared their PCSK9 levels to the patients who did not go on to develop these organ failures. PCSK9 levels are significantly higher upon presentation in those who progress to cardiovascular and respiratory failure compared to those who do not develop these organ dysfunctions (fig. 5a, b). Interestingly, following admission, PCSK9 levels continued to increase in those with cardiovascular or respiratory failure.

We also sought to confirm the findings of other authors [3-7] that very low levels of total, HDL and LDL cholesterol are associated with the development of severe sepsis. At presentation to the Emergency Department, we found much lower levels of total cholesterol, HDL and LDL in patients who went on to develop cardiovascular or respiratory failure as a result of their sepsis compared to patients with sepsis but without subsequent cardiovascular or respiratory failure (table 2). Given our recent in- sight into the critical role played by PCSK9 [1], this suggests that the early decline in cholesterol as well as hepatic inflammatory transcriptional activation may trigger increases in PCSK9, thus reducing the LDLR-mediated clearance of bacterial toxins.

\section{Discussion}

To our knowledge, this is the first report describing markedly increased plasma PCSK9 levels in human sepsis and the correlation of plasma PSCK9 levels with later cardiovascular and respiratory failure. PCSK9 levels associated with new onset respiratory and cardiovascular failure were $370(250-500)$ and $380(270-530) \mathrm{ng} / \mathrm{ml}$, respectively, versus $270(220-380) \mathrm{ng} / \mathrm{ml}$ in patients who did not go on to develop organ failure $(\mathrm{p}=0.003$ and 0.005 , respectively). We demonstrated that this effect has biological plausibility in that PCSK9 levels above $250 \mathrm{ng} / \mathrm{ml}$ progressively inhibited human hepatocyte endotoxin uptake. 


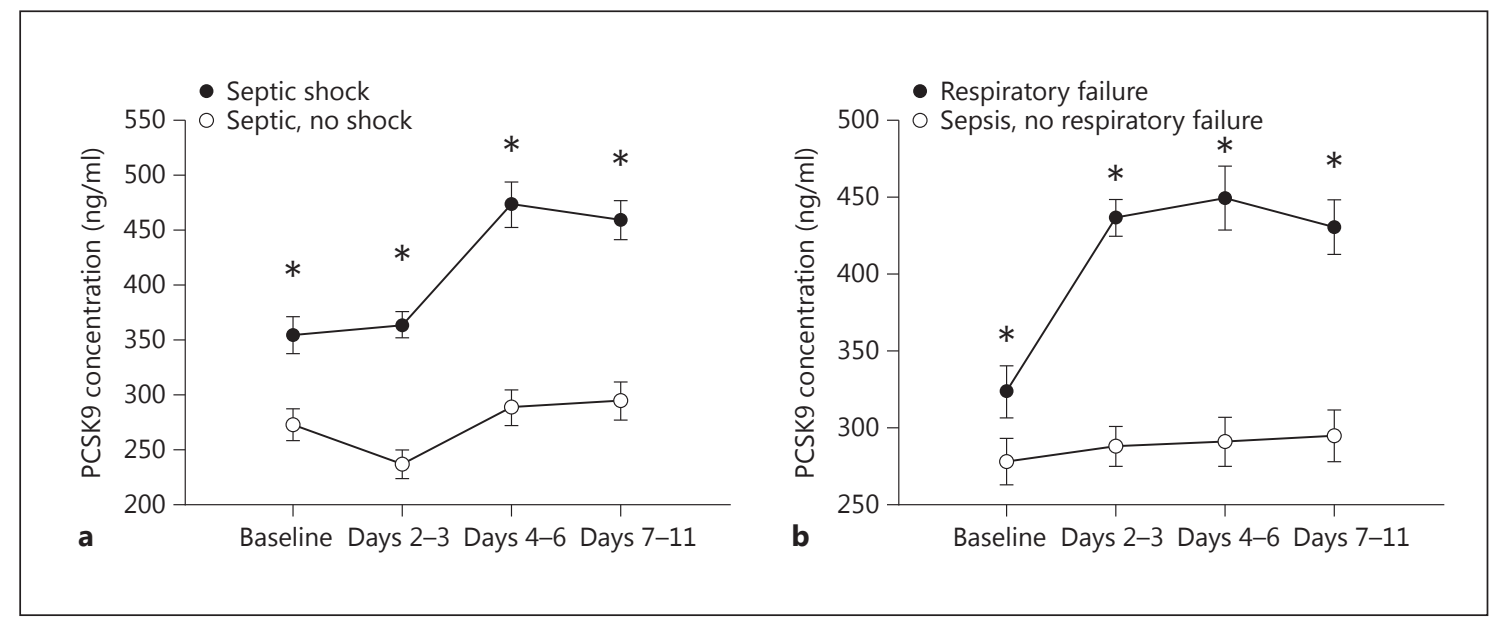

Fig. 5. PCSK9 levels according to the development of cardiovascular or respiratory failure due to sepsis. A total of 143 patients not on statins who triggered the sepsis protocol were followed during their admission for the development of organ failure(s). a PCSK9 plasma levels according to whether the patient developed cardiovascular failure. $\mathbf{b}$ PCSK9 plasma levels according to whether the patient developed respiratory failure. ${ }^{*} \mathrm{p}<0.05$.

Table 2. Lipid profiles and PCSK9 levels in all patients at presentation

\begin{tabular}{|c|c|c|c|c|c|c|}
\hline & $\begin{array}{l}\text { No cardio- } \\
\text { vascular failure }\end{array}$ & $\begin{array}{l}\text { Cardiovascular } \\
\text { failure }\end{array}$ & $\mathrm{p}$ value & $\begin{array}{l}\text { No respiratory } \\
\text { failure }\end{array}$ & $\begin{array}{l}\text { Respiratory } \\
\text { failure }\end{array}$ & $\mathrm{p}$ value \\
\hline $\mathrm{n}$ & 165 & 35 & & 140 & 60 & \\
\hline Total cholesterol, mmol/l & $3.04(2.21-3.81)$ & $2.08(1.59-2.79)$ & 0.0001 & $3.14(2.47-3.95)$ & $1.98(1.64-2.76)$ & 0.00001 \\
\hline LDL cholesterol, mmol/l & $1.48(0.93-2.10)$ & $0.95(0.56-1.36)$ & 0.0001 & $1.61(1.06-2.14)$ & $0.94(0.62-1.38)$ & 0.0001 \\
\hline HDL cholesterol, $\mathrm{mmol} / \mathrm{l}$ & $0.87(0.62-1.24)$ & $0.60(0.40-0.82)$ & 0.0001 & $0.92(0.68-1.30)$ & $0.60(0.40-0.82)$ & 0.001 \\
\hline Triglycerides, mmol/l & $1.14(0.78-1.58)$ & $1.12(0.78-1.37)$ & 0.495 & $1.15(0.78-1.60)$ & $1.08(0.78-1.39)$ & 0.18 \\
\hline
\end{tabular}

PCSK9 is a member of the proprotein convertase gene family discovered in 2003 [30]. The PCSK9 gene encodes a $74-\mathrm{kDa}$ proprotein that undergoes autocatalytic cleavage in the endoplasmic reticulum resulting in secretion of $\sim 14$ - and $\sim 60-\mathrm{kDa}$ fragments held together by non-covalent bonds $[31,32]$. Unlike other proprotein convertases, it has no further proteolytic activity [30]. The active PCSK9 protein circulating in the plasma binds the LDL receptor and, after cellular internalization, prevents recycling of the receptor back to the cell surface and promotes degradation of the receptor in the lysosome $[33,34]$. Therefore, inhibition of PCSK9 results in increased cell surface expression of LDL receptors and, consequently, increased LDL clearance and markedly decreased LDL cholesterol levels in humans [35]. The pivotal role of PCSK9 in cholesterol transport was discovered from genetic association studies. Loss of function genetic variants in PCSK9 resulted in a reduced sequestration of the LDL receptor and, as a result, decreased plasma LDL cholesterol concentrations [36, 37] and improved patient outcomes in atherosclerotic disease [38]; gain-of-function mutations have the opposite effect [30]. These observations led to intense interest in PCSK9 and to rapid development of PCSK9 inhibitors which, indeed, markedly reduce LDL cholesterol levels [39]. We recently discovered a marked benefit of reduced PCSK9 activity across a variety of murine models and in patients who have septic shock, implicating the LDLR (the primary target of PCSK9) as the most relevant pathway affected by PCSK9 [1]. PCSK9 inhibition using an anti-PCSK9 antibody increased the clearance of circulating pathogen toxins, reduced the septic in- 
flammatory response, and improved cardiovascular and survival outcomes in mice [1].

To understand the early effects of sepsis on PCSK9 and lipids, we studied early sepsis in the Emergency Department and obtained blood within $1 \mathrm{~h}$ of ED admission and subsequently over 11 days during the hospitalization. We found that plasma PCSK9 is rapidly increased in sepsis. These patients represent the broad base of the 'pyramid of sepsis', which includes sepsis, severe sepsis and septic shock. In this sepsis pyramid the base refers to all patients with suspected infection who have low blood pressure, and elevated heart and respiratory rates upon presentation. We understand that a new consensus definition will collapse to sepsis and septic shock. Prior reports of plasma PCSK9 in acute conditions are limited to trauma [40] and acute myocardial infarction [10]. Le Bras et al. [40] found that plasma PCSK9 doubled from an admission level of 231 to $480 \mathrm{ng} / \mathrm{ml}$ in severe trauma, and the peak levels were correlated with poor outcome, including length of stay in the intensive care unit and duration of mechanical ventilation. PCSK9 levels were more modestly increased by $20-30 \%$ during angiography for acute myocardial infarction in a twocohort, case-control retrospective review [10]. Similar to values reported in the literature [41] for later sepsis, lipids in our cohort were dramatically decreased in very early sepsis. We speculate that the decrease in lipids led to the increase in plasma PCSK9 because an increase of PCSK9 would be expected to increase lipid levels. However, this remains an association rather than proven causation.

To understand the effects of increasing PCSK9 levels on endotoxin uptake, we evaluated E. coli endotoxin uptake in cultured human hepatocytes. We found that PCSK9 greater than $250 \mathrm{ng} / \mathrm{ml}$ led to progressive inhibition of E. coli endotoxin uptake and a plateau at $60 \%$ inhibition at levels of about $3,000 \mathrm{ng} / \mathrm{ml}$. What constitutes a significant change in endotoxin levels with respect to the development or resolution of inflammatory organ failures? In data presented regarding the efficacy of endotoxin removal by the polymyxin blood perfusion device used in the EUPHAS and EUPHAS2 trial [42] presented by Dr. Massimo Antonelli (Canadian Critical Care Forum, Toronto, Canada, 2013), the therapy, when most efficacious, results in a $25 \%$ decline in endotoxin activity. This degree of removal was associated with rapid improvements in blood pressure and the need for vasopressors [42]. At the median levels of PCSK9 seen in our patient cohort the expected suppressive effect upon endotoxin clearance was nearly $20 \%$. Thus, it seems very plausible that high levels of PCSK9 are biologically active in early sepsis.

This study extends our knowledge of the role played by PCSK9 in sepsis in that we show a dramatic increase in circulating PCSK9 at the very earliest clinical encounter. We suggest that as PCSK9 levels increase in response to low cholesterol and direct inflammatory effects upon the liver, the probability of organ failure increases. Taken together, we believe that acute inhibition of PCSK9 activity is an attractive target for treating the spectrum of sepsis, severe sepsis and septic shock.

The strengths of our study include mechanistic evidence of PCSK9 being active at levels seen during sepsis, the extensive literature review involving a large sample size, and the recruitment of patients with early sepsis who are at increased risk of progressing to cardiorespiratory failure. Traditionally these patients are very difficult to recruit into clinical trials and our institutional deferred consent process was crucial in allowing us access to very early biological samples. The limitations to our study include its single-centre observational nature, which only allowed us to speculate regarding the mechanism through which low cholesterol and elevated PCSK9 are linked to the development of organ failures.

\section{Acknowledgements}

Dr. John H. Boyd is a National Sanitarium Association Scholar, a Michael Smith Foundation for Health Research Scholar, and a recipient of a Providence Health Care Research Scholarship. Dr. James A. Russell received overhead funds (UBC/PHC) from the Canadian Institutes of Health Research (CIHR; SONRIS). The funding sources had no role in the design and conduct of the study, collection, analysis and interpretation of the data, or preparation, review or approval of the manuscript.

\section{Disclosure Statement}

J.A.R., K.R.W. and J.H.B. are founders of Cyon Therapeutics Inc., a biotechnology company focused on the inhibition of PCSK9 for the treatment of sepsis. Cyon Therapeutics had no role in the funding or interpretation of these data.

Dr. Russell reports patents owned by the University of British Columbia (UBC) that are related to PCSK9 inhibitor(s) and sepsis and related to the use of vasopressin in septic shock. Dr. Russell is an inventor on these patents. Dr. Russell is a founder, Director and shareholder in Cyon Therapeutics Inc. (developing a sepsis therapy). Dr. Russell has share options in Leading Biosciences Inc. (developing a sepsis therapeutic). Dr. Russell reports receiving consulting fees from Cubist Pharmaceuticals (now owned by Merck, formerly Trius Pharmaceuticals, developing antibiotics), Ferring 
Pharmaceuticals (which manufactures vasopressin and is developing selepressin), Grifols (which sells albumin), MedImmune (regarding sepsis), Leading Biosciences (developing a sepsis therapeutic), La Jolla Pharmaceuticals (developing a sepsis therapeutic), CytoVale Inc. (developing a sepsis diagnostic), Asahi Kesai (devel- oping a sepsis therapeutic), and Sirius Genomics Inc. (now closed, formerly involved in pharmacogenomics research in sepsis). Dr. Russell reports having received grant support from Sirius Genomics and Ferring Pharmaceuticals that was provided to and administered by UBC.

\section{References}

1 Walley KR, Thain KR, Russell JA, Reilly MP, Meyer NJ, Ferguson JF, Christie JD, Nakada TA, Fjell CD, Thair SA, et al: PCSK9 is a critical regulator of the innate immune response and septic shock outcome. Science Transl Med 2014;6:258ra143.

-2 Stein EA, Raal FJ: Insights into PCSK9, lowdensity lipoprotein receptor, and low-density lipoprotein cholesterol metabolism: of mice and man. Circulation 2013;127:2372-2374.

-3 Fraunberger P, Schaefer S, Werdan K, Walli AK, Seidel D: Reduction of circulating cholesterol and apolipoprotein levels during sepsis. Clin Chem Lab Med 1999;37:357-362.

4 Chiarla C, Giovannini I, Siegel JH: The relationship between plasma cholesterol, amino acids and acute phase proteins in sepsis. Amino Acids 2004;27:97-100.

$\checkmark 5$ Chien JY, Jerng JS, Yu CJ, Yang PC: Low serum level of high-density lipoprotein cholesterol is a poor prognostic factor for severe sepsis. Crit Care Med 2005;33:1688-1693.

6 Shor R, Wainstein J, Oz D, Boaz M, Matas Z, Fux A, Halabe A: Low serum LDL cholesterol levels and the risk of fever, sepsis, and malignancy. Ann Clin Lab Sci 2007;37:343-348.

>7 Lagrost L, Girard C, Grosjean S, Masson D, Deckert V, Gautier T, Debomy F, Vinault S, Jeannin A, Labbe J, et al: Low preoperative cholesterol level is a risk factor of sepsis and poor clinical outcome in patients undergoing cardiac surgery with cardiopulmonary bypass. Crit Care Med 2014;42:1065-1073.

-8 Antman EM, Anbe DT, Armstrong PW, Bates ER, Green LA, Hand M, Hochman JS, Krumholz HM, Kushner FG, Lamas GA, et al: ACC/ AHA guidelines for the management of patients with ST-elevation myocardial infarction; a report of the American College of Cardiology/American Heart Association Task Force on Practice Guidelines (Committee to Revise the 1999 Guidelines for the Management of Patients with Acute Myocardial Infarction). J Am Coll Cardiol 2004;44:E1E211.

$\checkmark 9$ Feingold KR, Moser AH, Shigenaga JK, Patzek SM, Grunfeld C: Inflammation stimulates the expression of PCSK9. Biochem Biophys Res Commun 2008;374:341-344.

10 Almontashiri NA, Vilmundarson RO, Ghasemzadeh N, Dandona S, Roberts R, Quyyumi AA, Chen HH, Stewart AF: Plasma PCSK9 levels are elevated with acute myocardial infarction in two independent retrospective angiographic studies. PLoS One 2014;9:e106294.
11 Arsenault BJ, Pelletier-Beaumont E, Almeras N, Tremblay A, Poirier P, Bergeron J, Despres JP: PCSK9 levels in abdominally obese men: association with cardiometabolic risk profile and effects of a one-year lifestyle modification program. Atherosclerosis 2014;236:321-326.

12 Awan Z, Dubuc G, Faraj M, Dufour R, Seidah NG, Davignon J, Rabasa-Lhoret R, Baass A: The effect of insulin on circulating PCSK9 in postmenopausal obese women. Clin Biochem 2014;47:1033-1039.

13 Awan Z, Seidah NG, MacFadyen JG, Benjannet S, Chasman DI, Ridker PM, Genest J: Rosuvastatin, proprotein convertase subtilisin/ kexin type 9 concentrations, and LDL cholesterol response: the JUPITER trial. Clin Chem 2012;58:183-189.

14 Berthold HK, Seidah NG, Benjannet S, Gouni-Berthold I: Evidence from a randomized trial that simvastatin, but not ezetimibe, upregulates circulating PCSK9 levels. PLoS One 2013;8:e60095.

15 Blom DJ, Hala T, Bolognese M, Lillestol MJ, Toth PD, Burgess L, Ceska R, Roth E, Koren MJ, Ballantyne CM, et al: A 52-week placebocontrolled trial of evolocumab in hyperlipidemia. N Engl J Med 2014;370:1809-1819.

- 16 Costet P, Hoffmann MM, Cariou B, Guyomarc'h Delasalle B, Konrad T, Winkler K: Plasma PCSK9 is increased by fenofibrate and atorvastatin in a non-additive fashion in diabetic patients. Atherosclerosis 2010;212:246251.

17 Li S, Guo YL, Xu RX, Zhang Y, Zhu CG, Sun J, Qing P, Wu NQ, Jiang LX, Li JJ: Association of plasma PCSK9 levels with white blood cell count and its subsets in patients with stable coronary artery disease. Atherosclerosis 2014; 234:441-445.

18 Li S, Zhu CG, Guo YL, Xu RX, Zhang Y, Sun J, Li JJ: The relationship between the plasma PCSK9 levels and platelet indices in patients with stable coronary artery disease. J Atheroscler Thromb 2015;22:76-84.

19 Noguchi T, Kobayashi J, Yagi K, Nohara A, Yamaaki N, Sugihara M, Ito N, Oka R, Kawashiri MA, Tada H, et al: Comparison of effects of bezafibrate and fenofibrate on circulating proprotein convertase subtilisin/kexin type 9 and adipocytokine levels in dyslipidemic subjects with impaired glucose tolerance or type 2 diabetes mellitus: results from a crossover study. Atherosclerosis 2011;217: 165-170.
20 Raal F, Panz V, Immelman A, Pilcher G: Elevated PCSK9 levels in untreated patients with heterozygous or homozygous familial hypercholesterolemia and the response to highdose statin therapy. J Am Heart Assoc 2013; 2:e000028.

21 Taylor BA, Panza G, Pescatello LS, Chipkin S, Gipe D, Shao W, White CM, Thompson PD: Serum PCSK9 levels distinguish individuals who do not respond to high-dose statin therapy with the expected reduction in LDL-C. J Lipids 2014;2014:140723.

22 Zhang Y, Zhu CG, Xu RX, Li S, Guo YL, Sun J, Li JJ: Relation of circulating PCSK9 concentration to fibrinogen in patients with stable coronary artery disease. J Clin Lipidol 2014;8: 494-500.

23 Kellum JA, Lameire N: Diagnosis, evaluation, and management of acute kidney injury: a KDIGO summary (part 1). Crit Care 2013;17: 204.

24 Mehta RL, Kellum JA, Shah SV, Molitoris BA, Ronco C, Warnock DG, Levin A: Acute kidney injury network: report of an initiative to improve outcomes in acute kidney injury. Crit Care 2007;11:R31.

25 Bellomo R, Ronco C, Kellum JA, Mehta RL, Palevsky P: Acute renal failure - definition, outcome measures, animal models, fluid therapy and information technology needs: the Second International Consensus Conference of the Acute Dialysis Quality Initiative (ADQI) Group. Crit Care 2004;8:R204-R212.

26 Russell JA, Walley KR, Singer J, Gordon AC, Hebert PC, Cooper DJ, Holmes CL, Mehta S, Granton JT, Storms MM, et al: Vasopressin versus norepinephrine infusion in patients with septic shock. N Engl J Med 2008;358: 877-887.

27 Linder A, Fjell C, Levin A, Walley KR, Russell JA, Boyd JH: Small acute increases in serum creatinine are associated with decreased longterm survival in the critically ill. Am J Respir Crit Care Med 2014;189:1075-1081.

28 Wong HR, Lindsell CJ, Pettila V, Meyer NJ, Thair SA, Karlsson S, Russell JA, Fjell CD, Boyd JH, Ruokonen E, et al: A multibiomarker-based outcome risk stratification model for adult septic shock. Crit Care Med 2014;42: 781-789.

29 Padkin A, Goldfrad C, Brady AR, Young D, Black N, Rowan K: Epidemiology of severe sepsis occurring in the first $24 \mathrm{~h}$ in intensive care units in England, Wales, and Northern Ireland. Crit Care Med 2003;31:2332-2338. 
30 Horton JD, Cohen JC, Hobbs HH: Molecular biology of PCSK9: its role in LDL metabolism. Trends Biochem Sci 2007;32:71-77.

-31 Benjannet S, Rhainds D, Essalmani R, Mayne J, Wickham L, Jin W, Asselin MC, Hamelin J, Varret M, Allard D, et al: NARC-1/PCSK9 and its natural mutants: zymogen cleavage and effects on the low density lipoprotein (LDL) receptor and LDL cholesterol. J Biol Chem 2004;279:48865-48875.

32 Cunningham D, Danley DE, Geoghegan KF, Griffor MC, Hawkins JL, Subashi TA, Varghese AH, Ammirati MJ, Culp JS, Hoth LR, et al: Structural and biophysical studies of PCSK9 and its mutants linked to familial hypercholesterolemia. Nat Struct Mol Biol 2007; 14:413-419.

-33 Zhang DW, Lagace TA, Garuti R, Zhao Z, McDonald M, Horton JD, Cohen JC, Hobbs HH: Binding of proprotein convertase subtilisin/ kexin type 9 to epidermal growth factor-like repeat $\mathrm{A}$ of low density lipoprotein receptor decreases receptor recycling and increases degradation. J Biol Chem 2007;282:1860218612.
34 Tveten K, Strom TB, Berge KE, Leren TP: CSK9-mediated degradation of the LDL receptor generates a $17 \mathrm{kDa}$ C-terminal LDL receptor fragment. J Lipid Res 2013;54:15601566.

35 Stein EA, Mellis S, Yancopoulos GD, Stahl N, Logan D, Smith WB, Lisbon E, Gutierrez M, Webb C, Wu R, et al: Effect of a monoclonal antibody to PCSK9 on LDL cholesterol. N Engl J Med 2012;366:1108-1118.

36 Cohen JC, Boerwinkle E, Mosley TH Jr, Hobbs HH: Sequence variations in PCSK9, low LDL, and protection against coronary heart disease. N Engl J Med 2006;354:12641272.

37 Musunuru K, Lettre G, Young T, Farlow DN, Pirruccello JP, Ejebe KG, Keating BJ, Yang Q, Chen $\mathrm{MH}$, Lapchyk N, et al: Candidate gene association resource (CARe): design, methods, and proof of concept. Circ Cardiovasc Genet 2010;3:267-275.

38 Kathiresan S, Voight BF, Purcell S, Musunuru K, Ardissino D, Mannucci PM, Anand S, Engert JC, Samani NJ, Schunkert H, et al: Genome-wide association of early-onset myocardial infarction with single nucleotide polymorphisms and copy number variants. Nat Genet 2009;41:334-341.
39 King A: Lipids: antibodies against PCSK9 - a new era of therapy. Nat Rev Cardiol 2013;10: 1.

40 Le Bras M, Roquilly A, Deckert V, Langhi C, Feuillet F, Sebille V, Mahe PJ, Bach K, Masson D, Lagrost L, et al: Plasma PCSK9 is a late biomarker of severity in patients with severe trauma injury. J Clin Endocrinol Metab 2013; 98:E732-E736.

41 Dellinger RP, Levy MM, Rhodes A, Annane D, Gerlach H, Opal SM, Sevransky JE, Sprung CL, Douglas IS, Jaeschke R, et al: Surviving sepsis campaign: international guidelines for management of severe sepsis and septic shock: 2012. Crit Care Med 2013;41:580-637.

42 Cruz DN, Antonelli M, Fumagalli R, Foltran F, Brienza N, Donati A, Malcangi V, Petrini F, Volta G, Bobbio Pallavicini FM, et al: Early use of polymyxin $B$ hemoperfusion in abdominal septic shock: the EUPHAS randomized controlled trial. JAMA 2009;301:2445-2452. 